Research Paper

\title{
Trends and Outcomes of Sentinel Lymph Node Biopsy in Early-stage Vulvar Squamous Cell Carcinoma: A Population-based Study
}

\author{
Juan Zhou ${ }^{1 *}$, Wen-Wen Zhang ${ }^{2 *}$, Xue-Ting $C^{2}{ }^{3}$, San-Gang Wu ${ }^{4}$, Jia-Yuan Sun², Qiong-Hua Chen ${ }^{\bowtie}$, \\ Zhen-Yu He${ }^{2 \bowtie}$ \\ 1. Department of Obstetrics and Gynecology, the First Affiliated Hospital of Xiamen University, Xiamen 361003, People's Republic of China \\ 2. Department of Radiation Oncology, Sun Yat-sen University Cancer Center, State Key Laboratory of Oncology in South China, Collaborative Innovation \\ Center of Cancer Medicine, Guangzhou 510060, People's Republic of China \\ 3. Eye Institute of Xiamen University, Fujian Provincial Key Laboratory of Ophthalmology and Visual Science, Medical College, Xiamen University, Xiamen \\ 361005, People's Republic of China \\ 4. Department of Radiation Oncology, Xiamen Cancer Hospital, the First Affiliated Hospital of Xiamen University, Xiamen 361003, People's Republic of China \\ *Juan Zhou and Wen-Wen Zhang contributed equally to this work.
}

$\square$ Corresponding authors: Qiong-Hua Chen, Department of Obstetrics and Gynecology, the First Affiliated Hospital of Xiamen University, Xiamen 361003, People's Republic of China. Tel. +86 592 2139707; Fax. +86 592 2137322; E-mail. chenqionghuaxmu@126.com and Zhen-Yu He, Department of Radiation Oncology, Sun Yat-sen University Cancer Center, State Key Laboratory of Oncology in South China, Collaborative Innovation Center of Cancer Medicine, 651 Dongfeng Road East, Guangzhou 510060, People's Republic of China; Tel: +86 20 87343543; Fax: +86 2087343392 E-mail. hezhy@sysucc.org.cn

(C) Ivyspring International Publisher. This is an open access article distributed under the terms of the Creative Commons Attribution (CC BY-NC) license (https:// creativecommons.org/licenses/by-nc/4.0/). See http://ivyspring.com/terms for full terms and conditions.

Received: 2017.11.27; Accepted: 2018.01.13; Published: 2018.04.30

\begin{abstract}
Purpose: To compare trends and outcomes between lymphadenectomy and sentinel lymph node biopsy (SLNB) in node-negative early-stage vulvar squamous cell carcinoma (SCC) using a population-based cancer registry.

Methods: Patients with vulvar SCC registered on the Surveillance, Epidemiology, and End Results program between 2003 and 2013 were identified. Statistical analysis was performed using Cox regression proportional hazards to calculate hazard ratio $(\mathrm{HR})$ and $95 \%$ confidence interval $(\mathrm{Cl})$. A 1:1 propensity score matching (PSM) method was performed to minimize selection bias.

Results: A total of 1475 patients were identified, including 1346 (91.3\%) who received lymphadenectomy and $129(8.7 \%)$ who underwent SLNB. The proportion of patients receiving SLNB increased between 2008 and 2013 compared with the years 2003-2007 (13.9\% vs. 3.7\%, $p<0.001)$. Five-year cause-specific survival (CSS) in patients who received lymphadenectomy and SLNB was $91.8 \%$ and $92.9 \%$, respectively $(p$ $=0.912$ ), and 5 -year overall survival (OS) was $77.5 \%$ and $82.5 \%$, respectively $(p=0.403)$. SLNB was not associated with an decrease in CSS (HR 1.024, 95\% Cl 0.474-2.213, $p=0.952)$ or OS (HR $0.874,95 \% \mathrm{Cl}$ $0.541-1.410, p=0.581$ ) in univariate and multivariate analyses. A total of 115 pairs were selected by PSM and survival analysis also showed comparable CSS $(p=0.481)$ and OS $(p=0.545)$ between lymphadenectomy and SLNB.

Conclusions: There is an increasing trend toward SLNB in the treatment of patients with node-negative early-stage vulvar SCC, and survival is comparable between lymphadenectomy and SLNB.
\end{abstract}

Key words: Vulvar cancer, Squamous cell carcinoma, Lymphadenectomy, Sentinel lymph node biopsy, Survival

\section{Introduction}

Vulvar cancer is a rare gynecologic malignancy, accounting for approximately 3-5\% of all gynecologic malignancies. Squamous cell carcinoma (SCC) contributes approximately $85-90 \%$ of all vulvar cancers $(1,2)$. The incidence of vulvar cancer has increased in the last decade, probably due to a rise in human papilloma virus infection and lichen sclerosus, and prolonged human life expectancy, with 
peak incidence in the seventh decade of life (1,3-5). The presence of lymph node involvement is the most important prognostic factor in vulvar SCC $(1,6,7)$. Five-year survival rates were approximately $70-98 \%$ in node-negative patients, while only $12-41 \%$ for those with lymph node metastasis (7).

Systemic inguinofemoral lymphadenectomy is considered a standard surgical procedure for vulvar SCC patients with $>1 \mathrm{~mm}$ depth of invasion. Currently, lymphatic mapping and subsequent sentinel lymph node biopsy (SLNB) is the standard procedure in early-stage breast cancer and melanoma $(8,9)$. The incidence of inguinofemoral lymph node involvement for early-stage invasive vulvar SCC with clinically node negative is less than $30 \%$; therefore, inguinofemoral lymphadenectomy could be omitted in about $70 \%$ of those patients, making SLNB an acceptable method in the management of early-stage vulvar SCC with negative groin nodes (10-12). In 2008, the GROningen INternational Study on Sentinel nodes in Vulvar cancer (GROINSS-V) I was a prospective international observational study, which included the patients with early-stage vulvar SCC with unifocal tumors less than $4 \mathrm{~cm}$ in diameter who do not have evidence of suspicious groin nodes at palpation, the results showed that patients with a negative sentinel lymph node (SLN) appears to be safe to omit a complete inguinofemoral lymphadenectomy (13). In 2012, the results obtained in the gynecologic oncology group (GOG)-173 trial demonstrated similar results (14). Since these two seminal trials were published, the SLNB procedure has been integrated in the standard treatment for a selected group of patients with vulvar SCC world-wide (15). However, although complete lymphadenectomy results in a reduced quality of life (QoL), most early-stage vulvar cancer patients would choose complete lymphadenectomy over SLNB due to the fear of cancer recurrence (16).

Although several studies have found a low groin recurrence rate in patients undergoing SLNB (17-20), no randomized controlled trials have compared the effect of lymphadenectomy with SLNB on outcomes in vulvar SCC, because of the rarity of the disease. In this study, we used a population-based cancer registry (Surveillance, Epidemiology, and End Results, SEER) to compare trends and outcomes between lymphadenectomy and SLNB in nodenegative early-stage vulvar SCC.

\section{Materials and Methods}

\section{Patients}

The SEER program, a database maintained by the National Cancer Institute, includes demographics, incidence, and cancer-specific survival data for approximately $28 \%$ of the United States population (21). Our study included patients with vulvar cancer registered on the database between 2003 and 2013. Patients who met the following criteria were included: 1) histologically confirmed vulvar SCC; 2) American Joint Committee on Cancer 6th edition tumor stage (T-stage) T1-2 with tumor size $<4 \quad \mathrm{~cm}$; 3) node-negative disease who received lymphadenectomy or SLNB; 4) no preoperative or postoperative radiotherapy; 5) the availability of variables including age, race/ethnicity, grade, marital status, and the number of removed lymph nodes.

The following variables were collected from the SEER database: year of diagnosis, age, race/ethnicity, marital status, grade, T-stage, tumor size, and type of lymph node management. The primary survival outcomes of the study were cause-specific survival (CSS) and overall survival (OS). CSS was calculated as time from initial diagnosis to the date of death due to vulvar cancer. OS was calculated as the time between initial diagnosis and the date of death or last follow-up.

\section{Statistical analysis}

Descriptive statistics for patient demographics and clinicopathologic characteristics were analyzed for comparison between the types of lymph node procedure using Chi-square test and Fisher's exact test. A 1:1 match was used based on the propensity score matching (PSM) method to minimize selection bias using the following variables: age, race/ethnicity, grade, tumor size, and marital status $(22,23)$. CSS and OS rates were calculated using the Kaplan-Meier method and compared using the log-rank test. Cox univariate and multivariate analyses were used to calculate hazard ratios (HRs) and their 95\% confidence intervals (CIs) for adverse prognostic factors of survival outcomes. Statistical analyses were performed using SPSS version 22.0 (IBM Corporation, Armonk, USA) and a $p$ value $<0.05$ was considered statistically significant.

\section{Results}

A total of 1475 patients who met the inclusion criteria were identified, with a median age of 65 years (range 23-101 years). The patient demographics and clinicopathologic characteristics are listed in Table 1. Of the 1475 patients, $1346 \quad(91.3 \%)$ received lymphadenectomy and 129 (8.7\%) underwent SLNB. The median number of lymph nodes removed in patients who underwent lymphadenectomy and SLNB was 9 (range 1-44), and 2 (range 1-11), respectively. The percentage of patients who received SLNB was significant increase between 2008 and 2013 
compared with the years $2003-2007$ (13.9\% vs. 3.7\%, $p$ $<0.001$ ) (Figure 1). Patients with stage T1 disease were more likely to have undergone SLNB $(p=0.002)$. There were no significant differences in age, race/ethnicity, and marital status between the two lymph node procedures.

Table 1. Characteristics of 1475 vulvar squamous cell carcinoma patients based on type of lymph node management.

\begin{tabular}{lllll}
\hline Variables & $n$ & SLNB & Non-SLNB $p$ \\
\hline Age (years) & & & & \\
$<50$ & 236 & $20(15.5)$ & $216(16.0)$ & 0.809 \\
$50-64$ & 488 & $46(35.7)$ & $442(32.8)$ & \\
$\geq 65$ & 751 & $63(48.8)$ & $688(51.1)$ & \\
Race/ethnicity & & & & \\
Non-Hispanic White & 1222 & $108(83.7)$ & $1114(82.8)$ & 0.066 \\
Non-Hispanic Black & 97 & $4(3.1)$ & $93(6.9)$ & \\
Hispanic & 112 & $9(7.0)$ & $103(7.7)$ & \\
Other and unknown & 44 & $8(6.2)$ & $36(2.7)$ & \\
Grade & & & & \\
Well differentiated & 512 & $46(35.7)$ & $466(34.6)$ & 0.716 \\
Moderately differentiated & 744 & $67(52.0)$ & $677(50.3)$ & \\
Poorly/undifferentiated & 219 & $16(12.4)$ & $203(15.1)$ & \\
T-stage (AJCC 6th) & & & & \\
T1 & 899 & $95(73.6)$ & $804(59.7)$ & 0.002 \\
T2 & 576 & $34(26.4)$ & $542(40.3)$ & \\
Tumor size (mm) & & & & \\
1-10 & 400 & $46(35.7)$ & $354(26.3)$ & 0.015 \\
11-20 & 499 & $49(38.0)$ & $450(33.4)$ & \\
21-30 & 404 & $23(17.8)$ & $381(28.3)$ & \\
31-39 & 172 & $11(8.5)$ & $161(12.0)$ & \\
Marital status & & & & \\
Married & 663 & $63(48.8)$ & $600(44.6)$ & 0.366 \\
Divorced & 208 & $17(13.2)$ & $191(14.2)$ & \\
Single & 236 & $14(10.9)$ & $222(16.5)$ & \\
Widowed & 368 & $35(27.1)$ & $333(24.7)$ & \\
\hline A CC, Ams & & &
\end{tabular}

AJCC, American Joint Committee on Cancer; SLNB, sentinel lymph node biopsy; T, tumor.

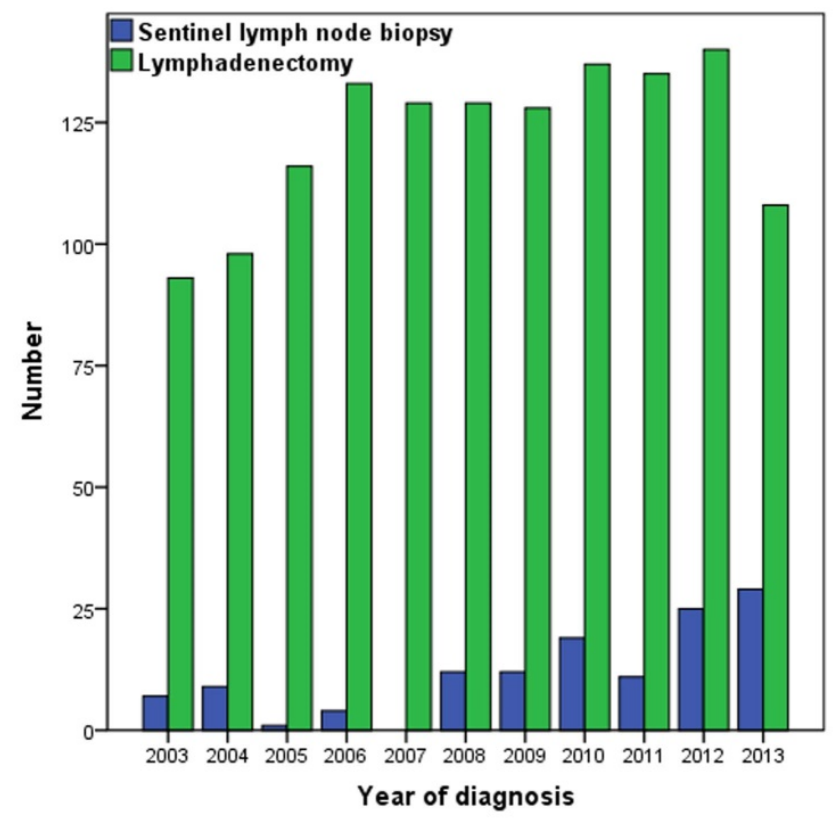

Figure 1. Number of patients who underwent lymphadenectomy and sentinel lymph node biopsy, 2003-2013.
The median follow-up time was 44 months (range 0-131 months). The 5-year CSS was 91.8\% and 92.9\% for lymphadenectomy and SLNB, respectively $(p=0.912)$ (Figure 2A), and 5-year OS was $77.5 \%$ and $82.5 \%$ for lymphadenectomy and SLNB, respectively $(p=0.403)$ (Figure 2B).

The univariate analysis results indicated that age, tumor size, and marital status were the prognostic factors affecting CSS and OS (Table 2). SLNB was not associated with decreased CSS (HR $0.958,95 \%$ CI $0.445-2.061, p=0.912$ ) or OS (HR 0.817, $95 \%$ CI 0.508-1.315, $p=0.405)$. When adjusted for age, tumor size, race, grade, and marital status, multivariate analysis still suggested that SLNB did not affect CSS (HR 1.024, 95\% CI 0.474-2.213, $p=$ 0.952 ) or OS (HR $0.874,95 \%$ CI $0.541-1.410, p=0.581$ ). Age, race, tumor size, and marital status were the independent predictors that influenced the survival outcomes (Table 3 ).

Table 2. Results of univariate analysis of 1475 vulvar squamous cell carcinoma patients.

\begin{tabular}{|c|c|c|c|c|c|c|}
\hline \multirow[t]{2}{*}{ Variables } & \multicolumn{3}{|l|}{ CSS } & \multicolumn{3}{|l|}{ OS } \\
\hline & HR & $95 \% \mathrm{CI}$ & $p$ & HR & $95 \% \mathrm{CI}$ & $p$ \\
\hline \multicolumn{7}{|l|}{ Age (years) } \\
\hline$<50$ & 1 & & & 1 & & \\
\hline $50-64$ & 2.491 & $0.947-6.554$ & 0.064 & 3.218 & 1.697-6.102 & $<0.001$ \\
\hline$\geq 65$ & 6.172 & $2.501-15.235$ & $<0.001$ & 9.039 & $4.940-16.538$ & $<0.001$ \\
\hline \multicolumn{7}{|l|}{ Race/ethnicity } \\
\hline $\begin{array}{l}\text { Non-Hispanic } \\
\text { White }\end{array}$ & 1 & & & 1 & & \\
\hline $\begin{array}{l}\text { Non-Hispanic } \\
\text { Black }\end{array}$ & 0.38 & 0.120-1.199 & 0.099 & 0.614 & $0.365-1.032$ & 0.066 \\
\hline Hispanic & 0.67 & $0.293-1.530$ & 0.342 & 0.694 & 0.436-1.104 & 0.123 \\
\hline $\begin{array}{l}\text { Other and } \\
\text { unknown }\end{array}$ & 1.914 & $0.887-4.128$ & 0.098 & 0.875 & $0.465-1.644$ & 0.677 \\
\hline \multicolumn{7}{|l|}{ Grade } \\
\hline $\begin{array}{l}\text { Well } \\
\text { differentiated }\end{array}$ & 1 & & & 1 & & \\
\hline $\begin{array}{l}\text { Moderately } \\
\text { differentiated }\end{array}$ & 1.274 & $0.824-1.970$ & 0.277 & 1.104 & $0.865-1.410$ & 0.426 \\
\hline $\begin{array}{l}\text { Poorly/undiffere } \\
\text { ntiated }\end{array}$ & 1.520 & $0.866-2.667$ & 0.145 & 1.157 & $0.829-1.614$ & 0.392 \\
\hline \multicolumn{7}{|l|}{$\begin{array}{l}\text { T-stage (AJCC } \\
\text { 6th) }\end{array}$} \\
\hline $\mathrm{T} 1$ & 1 & & & 1 & & \\
\hline $\mathrm{T} 2$ & 2.396 & $1.638-3.505$ & $<0.001$ & 1.985 & $1.596-2.469$ & $<0.001$ \\
\hline \multicolumn{7}{|c|}{ Tumor size $(\mathrm{mm})$} \\
\hline $1-10$ & 1 & & & 1 & & \\
\hline $11-20$ & 1.919 & $1.010-3.647$ & 0.046 & 1.513 & $1.082-2.116$ & 0.016 \\
\hline $21-30$ & 2.946 & $1.566-5.543$ & 0.001 & 2.241 & $1.607-3.126$ & $<0.001$ \\
\hline $31-39$ & 5.538 & $2.845-10.781$ & $<0.001$ & 3.452 & $2.382-5.001$ & $<0.001$ \\
\hline \multicolumn{7}{|l|}{ Marital status } \\
\hline Married & 1 & & & 1 & & \\
\hline Divorced & 0.673 & $0.341-1.330$ & 0.255 & 1.065 & $0.739-1.534$ & 0.737 \\
\hline Single & 0.75 & $0.399-1.411$ & 0.373 & 0.834 & $0.565-1.233$ & 0.364 \\
\hline Widowed & 1.574 & $1.030-2.405$ & 0.036 & 2.389 & $1.867-3.056$ & 0 \\
\hline \multicolumn{7}{|l|}{ SLNB } \\
\hline No & 1 & & & 1 & & \\
\hline Yes & 0.958 & $0.445-2.061$ & 0.912 & 0.817 & $0.508-1.315$ & 0.405 \\
\hline
\end{tabular}


Table 3. Multivariate analysis of 1475 vulvar squamous cell carcinoma patients.

\begin{tabular}{|c|c|c|c|c|c|c|}
\hline \multirow[t]{2}{*}{ Variables } & \multicolumn{3}{|l|}{ CSS } & \multicolumn{3}{|l|}{ OS } \\
\hline & HR & $95 \% \mathrm{CI}$ & $p$ & HR & $95 \% \mathrm{CI}$ & $p$ \\
\hline \multicolumn{7}{|l|}{ Age (years) } \\
\hline$<50$ & 1 & & & 1 & & \\
\hline $50-64$ & 2.452 & $0.932-6.453$ & 0.069 & 3.189 & $1.682-6.048$ & $\begin{array}{l}< \\
0.001\end{array}$ \\
\hline$\geq 65$ & 5.499 & $2.225-13.592$ & $\begin{array}{l}< \\
0.001\end{array}$ & 8.373 & $\begin{array}{l}4.572-15.33 \\
2\end{array}$ & $\begin{array}{l}< \\
0.001\end{array}$ \\
\hline \multicolumn{7}{|l|}{ Race/ethnicity } \\
\hline Non-Hispanic White & 1 & & & 1 & & \\
\hline Non-Hispanic Black & 0.592 & $0.185-1.900$ & 0.379 & 0.957 & $0.563-1.626$ & 0.870 \\
\hline Hispanic & 0.631 & $0.273-1.455$ & 0.28 & 0.682 & 0.425-1.095 & 0.113 \\
\hline Other and unknown & 2.201 & $1.010-4.798$ & 0.047 & 1.098 & $0.581-2.074$ & 0.774 \\
\hline \multicolumn{7}{|l|}{ Grade } \\
\hline Well differentiated & 1 & & & 1 & & \\
\hline $\begin{array}{l}\text { Moderately } \\
\text { differentiated }\end{array}$ & 1.243 & $0.800-1.932$ & 0.334 & 1.044 & $0.816-1.337$ & 0.732 \\
\hline $\begin{array}{l}\text { Poorly/undifferentiat } \\
\text { ed }\end{array}$ & 1.486 & $0.840-2.627$ & 0.173 & 1.102 & $0.784-1.547$ & 0.576 \\
\hline \multicolumn{7}{|l|}{ Tumor size (mm) } \\
\hline $1-10$ & 1 & & & 1 & & \\
\hline $11-20$ & 1.646 & $0.863-3.140$ & 0.13 & 1.344 & $0.960-1.881$ & 0.085 \\
\hline $21-30$ & 2.368 & $1.244-4.507$ & 0.009 & 1.753 & $1.253-2.451$ & 0.001 \\
\hline $31-39$ & 4.696 & $2.392-9.220$ & $\begin{array}{l}< \\
0.001\end{array}$ & 2.917 & $2.011-4.230$ & $\begin{array}{l}< \\
0.001\end{array}$ \\
\hline \multicolumn{7}{|l|}{ Marital status } \\
\hline Married & 1 & & & 1 & & \\
\hline Divorced & 0.706 & $0.355-1.405$ & 0.322 & 1.037 & $0.717-1.502$ & 0.846 \\
\hline Single & 0.782 & $0.412-1.487$ & 0.454 & 0.896 & $0.603-1.333$ & 0.589 \\
\hline Widowed & 0.881 & $0.557-1.395$ & 0.589 & 1.324 & $1.013-1.730$ & 0.040 \\
\hline \multicolumn{7}{|l|}{ SLNB } \\
\hline No & 1 & & & 1 & & \\
\hline Yes & 1.024 & $0.474-2.213$ & 0.952 & 0.874 & $0.541-1.410$ & 0.581 \\
\hline
\end{tabular}

Table 4. Characteristics of 115 matched pairs of patients

\begin{tabular}{lllll}
\hline Variables & $n$ & SLNB & Non-SLNB & $p$ \\
\hline Age (years) & 32 & 16 & 16 & 1 \\
$<50$ & 82 & 41 & 41 & \\
$50-64$ & 116 & 58 & 58 & \\
$\geq 65$ & & & & 1 \\
Race/ethnicity & 216 & 108 & 108 & \\
Non-Hispanic White & 2 & 1 & 1 & \\
Non-Hispanic Black & 10 & 5 & 5 & 1 \\
Hispanic & 2 & 1 & 1 & \\
Other and unknown & & & & \\
Grade & 80 & 40 & 40 & \\
Well differentiated & 120 & 60 & 60 & \\
Moderately differentiated & 30 & 15 & 15 & \\
Poorly/undifferentiated & & & & \\
Tumor size (mm) & 80 & 40 & 40 & \\
1-10 & 88 & 44 & 44 & \\
11-20 & 42 & 21 & 21 & \\
21-30 & 20 & 10 & 10 & \\
31-39 & & & & \\
Marital status & 116 & 58 & 58 & \\
Married & 26 & 13 & 13 & \\
Divorced & 26 & 13 & 13 & \\
Single & 62 & 31 & 31 & \\
Widowed & & & & \\
\hline
\end{tabular}

SLNB, sentinel lymph node biopsy.

We matched the patients using PSM, resulting in matched cohorts of 155 patients with lymphadenectomy and 115 patients with SLNB. The PSM cohorts are summarized in Table 4 . The survival analysis also showed comparable CSS $(p=0.481)$ (Figure 3A) and OS ( $p=0.545$ ) (Figure 3B) between lymphadenectomy and SLNB.

\section{Discussion}

In this study, we assessed the trends and outcomes of SLNB in patients with early-stage node-negative vulvar SCC, and our results showed an increasing trend toward SLNB, and survival outcomes were comparable between patients undergoing lymphadenectomy and SLNB in unmatched and matched populations.

The overall incidence of vulvar cancer increases with age, and our population-based study confirmed a median patient age of 65 years. Therefore, it is more important to investigate optimal treatment schedule to reduce the treatment-related complications and improve the QoL for this group of patients. Systemic inguinofemoral lymphadenectomy is considered the standard surgical procedure in patients with invasive vulvar SCC with $>1 \mathrm{~mm}$ invasion. However, complete inguinofemoral lymphadenectomy may lead to a higher rate of complications, including wound breakdown (20-40\%) and lymphedema (30-70\%) (24). Moreover, less than one-third of patients have inguinofemoral lymph node involvement, meaning routine inguinofemoral lymph node dissection exposes a large number of patients to potentially avoidable surgical complications (25). Currently, lymphatic mapping and subsequent SLNB is the standard procedure in early-stage breast cancer and melanoma $(8,9)$. Our results were similar to the previous study that the average number of removed lymph nodes was 9-10 for lymphadenectomy and 2-3 for SLNB (26), suggesting the extent of lymphadenectomy or SLNB in our population-based study was representative.

A population-based analysis from Germany by Rottmann et al. (27) found an increase in the proportion of patients with vulvar SCC undergoing SLNB, from $11.4 \%$ to $39.1 \%$ in the last two decades. A study from the United States by Cham et al. (17) also found that the proportion of vulvar cancer patients undergoing SLNB increased from $17.0 \%$ in 2006 to $39.1 \%$ in 2015 . Groin recurrence and survival were not affected by these changes and were likely accompanied by an improvement in QoL (27). However, in our study, prior to 2008 only $3.7 \%$ of vulvar SCC patients underwent SLNB, and although the proportion of patients receiving SLNB increased to $13.9 \%$ after 2008 , it was still lower than the aforementioned two studies. The rate of SLNB increased after 2008 following the publication of the 
results of the GROINSS-V-I (13). A previous SEER study indicated that only $5.1 \%$ of patients received SLNB between 2004 and 2008 (28). It is still unclear why there are differences between the SLNB rate in our study and the studies by Rottmann et al.(27) and Cham et al. (17). The differences in the study population may be the main reason contributing to the conflicting results. In addition, the rarity of the disease may limit the potential for individual surgeons to develop the technical skills for SLNB procedure. An expert panel recommended in 2009 that surgeons conduct 10 SLNB procedures followed by complete lymphadenectomy to confirm SLNB findings before conducting SLNB alone for appropriately selected patients (29). Therefore, for gynecologic oncologists who rarely see patients with vulvar cancer, it is appropriate to refer patients to a high-volume center or surgeon. SLNB should still be considered as an experimental approach that should not be routinely performed by gynecologic oncologists outside referral centers.

There have been no randomized trials to
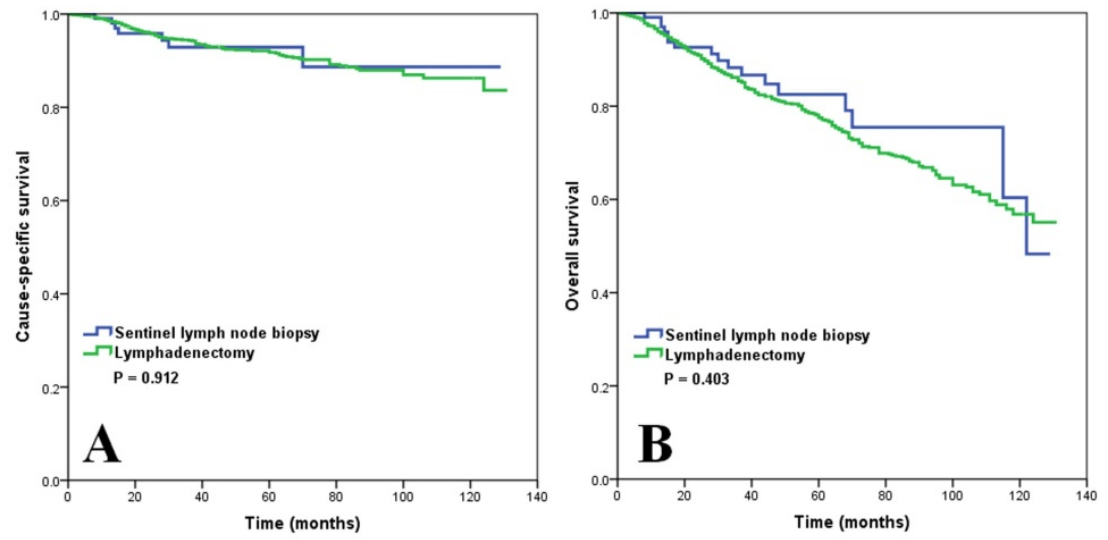

Figure 2. Survival comparison (A, cause-specific survival; B, overall survival) in patients with vulvar squamous cell carcinoma based on the type of lymph node management before propensity score matching.
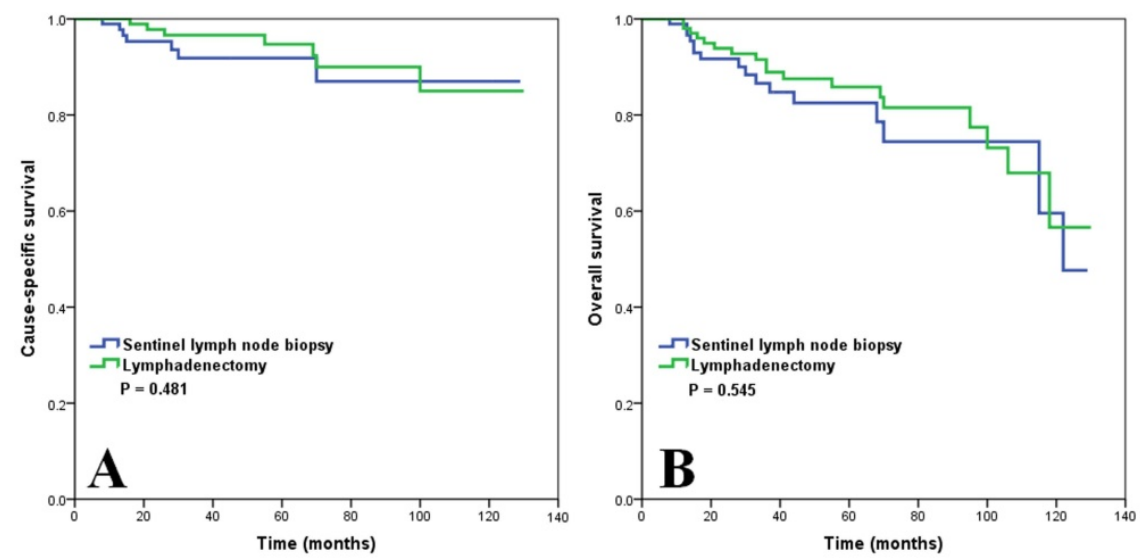

Figure 3. Survival comparison (A, cause-specific survival; $B$, overall survival) in patients with vulvar squamous cell carcinoma based on the type of lymph node management after propensity score matching. compare the effect on outcomes between lymphadenectomy and SLNB in vulvar SCC due to the rarity of the disease. The results of GROINSS-V-I and GOG-173 trials showed that SLNB in vulvar cancer had a high sensitivity (92-94\%) for the identification of SLN metastases and a low false-negative predictive value $(2.0-2.9 \%)$ in a selected group of patients $(13,14)$. Several studies have found that SLNB is the most cost-effective treatment strategy for management of early-stage vulvar cancer because of lower costs of primary treatment, lower risk of treatment-related complications, and better QoL (30-33). However, most of patients would choose complete lymphadenectomy over SLNB due to the fear of cancer recurrence (16). Therefore, more studies are needed to further delineate the application and outcomes of SLNB in vulvar cancer.

Groin recurrence rate was only $2.3 \%$ for unifocal vulvar disease in the GROINSS-V-I trial, and the 3 -year disease-specific survival rate was 97\% (13). After a median follow-up of 105 months, the isolated groin recurrence rate was $2.5 \%$ for SLN-negative patients, and the disease-specific survival rate was $91 \%$ at 10 years (18). Robison et al. (19) recently reported SLNB results for 69 patients and found groin recurrence was $5.3 \%$ in SLN-negative patients. A 20-year analysis of 128 patients by Brammen et al. (20) included 46 patients who received SLNB, and no groin recurrence was observed in these patients. The long-term results of SLNB procedure in patients with node-negative breast cancer was also shown an extremely low rate of axillary recurrence $(0.2 \%)$ (34). In our study, the SLNB procedure was not associated with an increased risk of all-cause mortality compared with lymphadenectomy. Therefore, the advantages of the SLNB procedure must be disseminated for the benefit of as many patients as possible to decrease morbidity and improve QoL.

Currently, there are corresponding recommendations for patients who are eligible for SLNB. Patients with tumors that are unifocal, less than $<4 \mathrm{~cm}$ in diameter, and with no evidence of 
lymph node involvement by preoperative assessment, are eligible for SLNB (35), while patients with multifocal disease, clinically suspicious groin nodes, or a tumor located in the midline are unsuitable $(13,14,24)$. In addition, patients who have undergone preoperative radiotherapy/chemotherapy should probably be excluded because damage to the lymph vessels may affect the SLNB procedure (36).

We need to acknowledge several limitations to our study. First, it will have the inherent bias of any retrospective study. Second, details on the extent of lymphadenectomy, the method of SLN identification procedures, and the patterns of disease recurrence are lacking in the SEER database. In addition, the radiological staging and histopathological ultrastaging are also not included in the SEER database. However, due to the relatively rare incidence of the disease, it is difficult to conduct randomized controlled trials to compare the effect of lymphadenectomy and SLNB on patient survival. The primary strength of our study is that we used population-based data to compare the outcomes of the two types of lymph node management.

\section{Conclusion}

In conclusion, our results suggest an increasing trend toward SLNB in patients with node-negative early-stage vulvar SCC, and survival is comparable between patients undergoing lymphadenectomy and SLNB. Considering that most vulvar cancers are in the elderly, SLNB has an important part of the management of these patients to decrease surgery-related complications and improve the QoL. More prospective studies are needed to confirm our results.

\section{Acknowledgment}

This work was supported by grants from the Natural Science Foundation of Fujian Province (No. 2015J01550, 2013D001), the Medical Innovation Foundation of Fujian Province (No. 2015-CXB-34), and the Foundation for Young Scholar of Fujian Provincial Health Department (No. 2014-ZQN-ZD$31)$.

\section{Competing Interests}

The authors have declared that no competing interest exists.

\section{References}

1. Gadducci A, Cionini L, Romanini A, et al. Old and new perspectives in the management of high-risk, locally advanced or recurrent, and metastatic vulvar cancer. Crit Rev Oncol Hematol. 2006;60(3):227-241.

2. Hacker NF, Eifel PJ, van der Velden J. Cancer of the vulva. Int J Gynaecol Obstet. 2012;119 Suppl 2:S90-S96.
3. Bleeker MC, Visser PJ, Overbeek LI, et al. Lichen Sclerosus: Incidence and Risk of Vulvar Squamous Cell Carcinoma. Cancer Epidemiol Biomarkers Prev. 2016;25(8):1224-1230.

4. Schuurman MS, van den Einden LC, Massuger LF, et al. Trends in incidence and survival of Dutch women with vulvar squamous cell carcinoma. Eur J Cancer. 2013;49(18):3872-3880.

5. de Hullu JA, van der Zee AG. Surgery and radiotherapy in vulvar cancer. Crit Rev Oncol Hematol. 2006;60(1):38-58.

6. Gonzalez Bosquet J, Magrina JF, Gaffey TA, et al. Long-term survival and disease recurrence in patients with primary squamous cell carcinoma of the vulva. Gynecol Oncol. 2005;97(3):828-833.

7. Gadducci A, Tana R, Barsotti C, et al. Clinico-pathological and biological prognostic variables in squamous cell carcinoma of the vulva. Crit Rev Oncol Hematol. 2012;83(1):71-83.

8. Lyman GH, Temin S, Edge SB, et al. Sentinel lymph node biopsy for patients with early-stage breast cancer: American Society of Clinical Oncology clinical practice guideline update. J Clin Oncol. 2014;32(13):1365-1383.

9. Boada A, Tejera-Vaquerizo A, Ribero S, et al. Sentinel lymph node biopsy versus observation in thick melanoma: A multicenter propensity score matching study. Int J Cancer. 2018;142(3):641-648.

10. Hacker NF, Berek JS, Lagasse LD, et al. Management of regional lymph nodes and their prognostic influence in vulvar cancer. Obstet Gynecol. 1983;61(4):408-412.

11. Green TH Jr. Carcinoma of the vulva. A reassessment. Obstet Gynecol. 1978;52(4):462-469.

12. Iversen T, Aalders JG, Christensen A, et al. Squamous cell carcinoma of the vulva: a review of 424 patients, 1956-1974. Gynecol Oncol. 1980;9(3):271-279.

13. Van der Zee AG, Oonk MH, De Hullu JA, et al. Sentinel node dissection is safe in the treatment of early-stage vulvar cancer. J Clin Oncol. 2008;26(6):884-889.

14. Levenback CF, Ali S, Coleman RL, et al. Lymphatic mapping and sentinel lymph node biopsy in women with squamous cell carcinoma of the vulva: a gynecologic oncology group study. J Clin Oncol. 2012;30(31):3786-3791.

15. Covens A, Vella ET, Kennedy EB, et al. Sentinel lymph node biopsy in vulvar cancer: Systematic review, meta-analysis and guideline recommendations. Gynecol Oncol. 2015;137(2):351-361.

16. Farrell R, Gebski V, Hacker NF. Quality of life after complete lymphadenectomy for vulvar cancer: do women prefer sentinel lymph node biopsy? Int J Gynecol Cancer. 2014;24(4):813-819.

17. Cham S, Chen L, Burke WM, et al. Utilization and Outcomes of Sentinel Lymph Node Biopsy for Vulvar Cancer. Obstet Gynecol. 2016;128(4):754-760.

18. Te Grootenhuis NC, van der Zee AG, van Doorn HC, et al. Sentinel nodes in vulvar cancer: Long-term follow-up of the GROningen INternational Study on Sentinel nodes in Vulvar cancer (GROINSS-V) I. Gynecol Oncol. 2016;140(1):8-14.

19. Robison K, Roque D, McCourt C, et al. Long-term follow-up of vulvar cancer patients evaluated with sentinel lymph node biopsy alone. Gynecol Oncol. 2014;133(3):416-420.

20. Brammen L, Staudenherz A, Polterauer S, et al. Sentinel lymph node detection in vulvar cancer patients: a 20 years analysis. Hell J Nucl Med. 2014;17(3):184-189.

21. [Internet] Surveillance, Epidemiology, and End Results (SEER) Program (www.seer.cancer.gov) SEER*Stat Database: Incidence - SEER 18 Regs Custom Data (with chemotherapy recode), Nov 2015 Sub (2000-2013) <Katrina/Rita Population Adjustment> - Linked To County Attributes Total U.S., 1969-2014 Counties, National Cancer Institute, DCCPS, Surveillance Research Program, released July 2016, based on the November 2015 submission). www.seer.cancer.gov

22. Rosenbaum PR, Rubin DB. Constructing a control group using multivariate matched sampling methods that incorporate the propensity score. Am Stat. 1985,39(1):33-38.

23. Austin PC. An Introduction to Propensity Score Methods for Reducing the Effects of Confounding in Observational Studies. Multivariate Behav Res. 2011;46(3):399-424.

24. Robison K, Fiascone S, Moore R. Vulvar cancer and sentinel lymph nodes: a new standard of care? Expert Rev Anticancer Ther. 2014;14(9):975-957.

25. Sedlis A, Homesley H, Bundy BN, et al. Positive groin lymph nodes in superficial squamous cell vulvar cancer. A Gynecologic Oncology Group Study. Am J Obstet Gynecol. 1987;156(5):1159-1164.

26. Moore RG, DePasquale SE, Steinhoff MM, et al. Sentinel node identification and the ability to detect metastatic tumor to inguinal lymph nodes in squamous cell cancer of the vulva. Gynecol Oncol. 2003;89(3):475-479.

27. Rottmann M, Beck T, Burges A, et al. Trends in surgery and outcomes of squamous cell vulvar cancer patients over a 16-year period (1998-2013): a population-based analysis. J Cancer Res Clin Oncol. 2016;142(6):1331-1341.

28. Canlorbe G, Rouzier R, Bendifallah S, et al. Impact of sentinel node technique on the survival in patients with vulvar cancer: analysis of the Surveillance, Epidemiology, and End Results (SEER) database. Gynecol Obstet Fertil. 2012; 40(11):647-651. [Article in French]

29. Levenback CF, van der Zee AG, Rob L, et al. Sentinel lymph node biopsy in patients with gynecologic cancers Expert panel statement from the International Sentinel Node Society Meeting, February 21, 2008. Gynecol Oncol. 2009;114(2):151-156. 
30. Erickson BK, Divine LM, Leath CA 3rd, et al. Cost-effectiveness analysis of sentinel lymph node biopsy in the treatment of early-stage vulvar cancer. Int J Gynecol Cancer. 2014;24(8):1480-1485.

31. Sutton AJ, Barton P, Sundar S, et al. Cost-effectiveness of sentinel lymph node biopsy vs inguinofemoral lymphadenectomy in women with vulval cancer. Br J Cancer. 2013;109(10):2533-2547.

32. Novackova $\mathrm{M}$, Halaska MJ, Robova $\mathrm{H}$, et al. A prospective study in the evaluation of quality of life after vulvar cancer surgery. Int J Gynecol Cancer. 2015;25(1):166-173.

33. McCann GA, Cohn DE, Jewell EL, et al. Lymphatic mapping and sentinel lymph node dissection compared to complete lymphadenectomy in the management of early-stage vulvar cancer: A cost-utility analysis. Gynecol Oncol. 2015;136(2):300-304.

34. Toussaint A, Nogaret JM, Veys I, et al. Axillary recurrence rate in breast cancer patients with negative sentinel lymph node biopsy or containing micrometastases and without further lymphadenectomy: a monocentric review of 8 years and 481 cases. Breast J. 2011;17(4):337-342.

35. Brincat MR, Muscat Baron Y. Sentinel Lymph Node Biopsy in the Management of Vulvar Carcinoma: An Evidence-Based Insight. Int J Gynecol Cancer. 2017;27(8):1769-1773.

36. Levavi H, Sabah G, Hardoff R, Koren C, Gutman H. Failure of sentinel node identification following neo-adjuvant chemo-radiotherapy for locally advanced squamous cell carcinoma of the vulva. Eur J Gynaecol Oncol. 2003;24(5):433-434 